\title{
A Research on University Students' Love Attitude
}

\author{
LIU Di-fei \\ Education Department \\ Hefei University \\ Hefei, China \\ e-mail: liudifei@163.com
}

\author{
GAO Jie \\ Education Department \\ Hefei University \\ Hefei, China \\ e-mail: wbwldf@126.com
}

\begin{abstract}
Objective To dig into college students` Love Attitude and supply a reference for Quality education and Marriage-counseling in universities. Method To carried out experiments on 193 students from Hefei University on the basis of revised The Chinese Version of Revised the Love Attitude Scale and the Associative Test selfdesigned by the E-prime program. Results 1.Male students' scores are higher as to romance devotion and the total marks; the scores of those who had previous love experience in considering devotion are higher than those who did not; students from urban areas are more realistic to love than those from rural areas. 2. There is significant difference in the implicit test between single children and Non-only children and among the students who have different love experience. 3. The explicit attitude of university students about love differ from the implicit attitude; the dual attitude model has been proved.
\end{abstract}

Keywords- implicit attitude; explicit attitude; implicit associative test; love attitude

\section{INTRODUCTION}

Love attitude is the basic view and attitude towards issues concerning love, it is the reflection of one's philosophy and value [1]. Influenced and restricted by different economic condition, political system and cultural pattern, Love attitude projects different images in different historic periods and meanwhile develops with the pace of social advancement [2]. Love attitude of university students in the 21st century suggests the fundamental features of value orientation of marriage in this age. It also reflects the conditions of marriage and family in the future to some degree. Currently, university students stay in the age between 18 to 22. The physical sexual maturity and the psychological sexual development generate their need for love. The attention to love and marriage and the attempts to love have become part of their school life. Therefore, it is the psychological educators 'responsibility to know the love attitude of university students and to steer them appropriately during the process of sex education. It is one important task of building a harmonious campus.

Recently, domestic researches on love attitude have mainly focused on self-report like questionnaires and scales, or analytical summary of the figures in literature masterpieces and films, or the analysis of social phenomenon which shows the mass outlook of love in the transitional period of society [3]. However, all these are concluded from the explicit attitude towards love, a comparison between the explicit and the implicit outlook can hardly be found [4][5]. In this case, this research focuses on the comparison, hoping to provide solid and objective data to the quality education and marriage consultation in universities.

\section{Methods OF RESEARCHING}

\section{A. The target of researching}

Six out of ten departments in the South Campus of Hefei University have been chosen randomly, including three Liberal Arts departments and three Science Arts departments ranging from freshmen to juniors. Predicted test includes sending 239 LAS scales, the first time, 132 sent and 113 withdrew, withdraw rate $85.6 \%$; the second time, 107 sent and 107 withdrew, withdraw rate $100 \%$, total withdraw rate 92.1\%; 193 valid questionnaires, validity rate $87.7 \%$. Among the 193 valid questionnaires, 50 show a zero love experience, 25 show an ongoing love, 24 show a previous experience, 94 show a lack of information. The largest number of love experience is 8 .

During the real experiment, 85 LAS questionnaires sent, 82 withdrew, withdraw rate $96.47 \%$, 80 valid questionnaires, validity rate $94.12 \%$. Among the 80 testees there were 31 male and 49 female with the average age of 21.3 and the times of love from 0 to 8 . They came from 25 different majors in 10 departments, all of whom had a normal sight and the same mother tongue, Chinese. 77 of them joined the IAT implicit associative test, leaving 74 valid data.

\section{B. Tools for researching}

This test contains two parts, namely, the explicit and implicit attitudinal test on the love attitude. The LAS scale was used in the explicit test. The LAS scale made by Clyde Hendrick and Susan S. Hendrick takes the measure method of 5 point calculation which includes 42 questions. There are 6 sub-scales in it, they are romance test, entertainment test, companion test, realization test, tenure test and sacrifice test [6]. Revised LAS scale consists of 5 scales: romance test, companion test, realization test, tenure test and sacrifice test, altogether 35 questions. The retest reliability of the revised LAS scale is 0.717 , the retest reliability of the sub-scales ranges from 0.625 to 0.810 . The coefficient a of the whole scale is 0.759 while that of sub-scales ranges from 0.629 to 0.698 . 
The implicit attitude test relies mainly on IAT implicit associative test made by E-prime 2.0 program. The compatible task of this test is self with positive and non-self with negative, and the incompatible task is self with negative and non-self with positive [7][8]. The conceptual words are self and non-self with each being ten. The attributive words are positive and negative with each being ten. The materials in the test are all in Chinese [9].

Liker-type calculation is used to mark the six love type in the LAS collected, and to mark the love glossary got from the Internet. At last, 39 glossary are fixed. In the light of the evaluation results, 10 positive and 10 negative are chosen.

There is no time limit of this test. Usually the test takes about 15 minutes.

\section{The process of researching}

In trying to control the order of the two different types, some of the testees go the explicit first, others go oppositely.

The implicit associative test is carried out on the computer. The stimulating words show in the middle of the screen. Press F to limit them to the left, and J, right. There are 7 steps in total such as telling the attributive conception and the aim conception. The testees should do all the test after the tester gives the instructions. The computer will record the time and condition of their response.

\section{The collection and process of the data}

First, type all the data into the SPSS17.0 for systematic analysis. Next, filter and process the data collected by 74 computers, deleting the first two data before both compatible and incompatible task. Then, deleting the data with an error rate higher than 20\%. Convert any time less than 300 millisecond to 300 millisecond and any time more than 3,000 millisecond to 3,000 millisecond lest the testees respond without reading the question or respond when they are exhausted.

Logarithm equation should be made in advance and then average should be worked out. In the process of calculating the average, the time of wrongful calculation should also be included. The number of either compatible or incompatible data should be 18 , altogether 36 . The final valid data are 74 in total. When all of these are done, the value of IAT can be found in the difference of the average of part 4 minus the average of part7. After that, each single datum and score ought to be led into the SPSS17.0.

\section{RESULTS}

\section{A. The analysis of the explicit love attitude}

There are 18 students who belong to romance type and tenure type, 56 students who belong to companion type, reality and devotion type. The negative love attitude accounts for $24.3 \%$, the positive love attitude takes up $75.7 \%$. Therefore the conclusion is, the mainstream of the love attitude of university students is positive.

A further study shows that male students' scores are higher than female students as to romance, devotion and the total marks; the scores of those who had previous love experience in considering devotion are higher than those who did not; students from urban areas are more realistic to love than those from rural areas.

\section{B. The analysis of the implicit love attitude}

After counting the value of $\mathrm{R}(\mathrm{R}=$ the value of the logarithm of the incompatible task- the value of logarithm of the compatible task, namely, the quota if IAT), we discover that 36 of the $\mathrm{R}$ are negative in value, that accounts for $48.65 \%$. It shows that nearly half of the testees are negative as to the outlook of love, which does not correspond to the outcome of the explicit scale.

We checked the independent sample of $t$ and analyzed the single factor variance on the basis of the difference of gender, grade, subject, source of students, single child and love experience, the result comes as the following table I :

TABLE I . Test of the variation of the IAT quota of the implicit attitude

\begin{tabular}{cccc}
\hline Variable quantity & $\boldsymbol{d} \boldsymbol{f}$ & $\boldsymbol{t} \boldsymbol{F}$ & $\boldsymbol{p}$ \\
\hline Single children & 68 & -2.234 & $0.029^{*}$ \\
Love experience & 66 & 7.074 & $0.002^{* * *}$ \\
\hline
\end{tabular}

*shows a conspicuous difference of $\mathrm{P}$ on both side-test of 0.05 level

** shows a conspicuous difference of $\mathrm{P}$ on both side-test of 0.01 level

From the result we know that the IAT quota differ greatly in the aspect of single children love experience, especially in those whose love experience $(\mathrm{P}<0.01)$. For this reason, many comparisons were made after the analysis, the result showed that there was actually an obvious difference between those who had a love experience and those who did not. Students without an experience tend to act positively while those who had are more likely to behave negatively.

\section{The comparative analysis between the explicit test and} the implicit test

We analyzed the 5 types of the explicit and the implicit, the data of the IAT show as the following table2:

TABLE II.

The correlation analysis of IAT between explicit test and implicit test

\begin{tabular}{cccccccc}
\hline & & Total & Rom & Com & Rea & Ten & Sac \\
\cline { 2 - 8 } IAT & $\mathrm{r}$ & 0.101 & 0.030 & 0.059 & 0.136 & 0.023 & 0.055 \\
quota & $\mathrm{p}$ & 0.400 & 0.800 & 0.621 & 0.256 & 0.850 & 0.646 \\
\hline
\end{tabular}

(Rom is Romance type, Com is Companion, Rea is Realistic type, Ten is Tenure type, Sac is Sacrifice type)

From this we can know that there is no conspicuous relation between the IAT quota and explicit attitude. This indicates that what the two target audiences are different, and we inferred that different attitudes shall be taken to deal with different aspects of the object.

On this basis, we carried out the $\chi_{2}$ test to the 74 data. If the IAT quota surpass 0 , it means a positive attitude of the implicit tendency, vice versa. But the categorization of the explicit attitude is mainly based on 47questionaires. It owes romance and tenure type to negative, companion, realistic and sacrifice to positive. Deleting the 11 nullification 
questionnaires, there are 63 left, as the following table shows:

TABLE III. The result of chi-square test

Explicit

\begin{tabular}{|c|c|c|c|}
\hline \multirow{3}{*}{ Implicit } & \multirow[b]{2}{*}{ Positive } & Positive & Negative \\
\hline & & 19 & 10 \\
\hline & $\begin{array}{c}\text { Negativ } \\
e\end{array}$ & 27 & 7 \\
\hline & & 46 & 17 \\
\hline
\end{tabular}

This is a test of the relative sample of $\chi_{2}$, following the equation: $\chi^{2}=(\mathrm{A}-\mathrm{D})^{2} /(\mathrm{A}+\mathrm{D})=5.538$, $\mathrm{df}=(2-1) \times(2-1)=1$, after a reference to the distribution list, we get $\chi^{2} 0.05=3.84<\chi_{2}$, this proved the apparent variation mentioned before.

\section{DISCUSSION}

\section{A. The discussion of the explicit love attitude of the students in University}

The analysis of the data of the explicit love attitude shows that male students are more fond of romance and sacrifice type than female students. According to the theory of Lee, the romance type is in essence the desire for sex. It focuses on appearance and physical contact. An ancient Chinese saying goes that a beauty shows her charm, a gentleman reaches out his arm [10]. Male students pay attention on girls`appearance, this is consistent to what we have held in mind all the time. The sacrifice type is in essence the benefit for him. The students of this type devote all to the lover, care the opposite, and love the opposite without any return. They are patient enough. They neither demand nor envy the opposite. It may be related to the necessary characters for males which we advocate nowadays, such as responsibility, tolerance and so on. Those who had previous love experience score higher in the sacrifice type than those who did not $(p=0.0460)$. From this we can know that those who had previous love experience tend to cherish the hard-earned love, which agrees with some current ideas of people. So males who are over 30 years old and have several love experiences tend to be more suitable for marriage.

Students from urban areas score are higher than those from rural areas, from which we can infer that the students from urban areas are more realistic and rational than those from rural areas. Through the survey, we can find the main stream of the love attitude of university students is healthy and positive. The vast majority of students agreed on the sexual behavior before marriage, but they never do so.

This can show contradictory attitudes of college students. Meanwhile, we found that the vast majority of girls thought that having sexual behavior before marriage was not suitable, which was totally different from boys. It expressed that girls were more careful than boys on the sexual behavior before marriage, which was consistent with our usual cognitions.

\section{B. The discussion of the implicit love attitude of the students in University}

The implicit test showed a conspicuous difference of single children and love experience, especially love experience $(p<0.01)$. Then we went on the multiple comparisons and found that those who had previous love experience and those who had no love experience shared the significant difference. Those who had no love experience tended to the positive love outlook, and those who had previous love experience tended to the negative love outlook. Associating with former discussion, we can conclude that those who had previous love experience were more inclined to be sacrifice type than those who were in love. We can infer that in love experience, having previous love experience, the order from positive love outlook to negative love outlook was no love experience, having previous love experience and in love. From this we can see that love experience had a certain effect on one's emotional dedication. Those who were in love were more inclined to get.

C. The discussion of the relationship between the explicit love attitude and implicit love attitude of the students in University

The study showed that IAT index of implicit attitude had insignificant difference with the measurement of explicit attitude. It further proved that the two measured contents were for different objects. In addition, we further divided the explicitness and implicitness into positive and negative and then conducted the test. We got a result that it showed a conspicuous difference between explicit attitude and implicit attitude of the students in Hefei University, as a result, it proved the dual attitude model.

Now one of the controversial topics in the academic circle includes the relationship between explicit attitude and implicit attitude and meanwhile its behavior prediction. Which is better to predict the behavior, implicit attitude or explicit attitude? And the controversy lies in different aspects and different types. However, personally, it still has some difficulties to draw this conclusion from the survey, as it needs the self-assessment and assessment from others. Because of various reasons, we only collect the data of selfassessment, the results of $\chi^{2}$ test well illustrated this point.

From another point of view, namely, the psychology of the academic point of view, on the one hand, Crosby and other people discovered very early that on the behavioral aspect of social sensitivity, the predictive power of implicit attitude was stronger than that of explicit attitude. Nosek and Banaji thought it might reflect that the subjects had a tendency to conduct impression measurement during the process of explicit measurement. However, during the process of implicit measurement, this tendency of impression management was difficult to achieve. As this implicit test or some time after it, the subjects all said that this test made them feel rather inexplicable. "How could it be the test of love outlook?" Of course, this does not rule out the influence of other factors, such as the characteristics of the subjects group. But for the behavior with lower social 
sensitivity, the predictive power of explicit attitude is stronger than that of implicit attitude.

On the other hand, in the aspect of behavior that consciousness is difficult to control; the predictive power of implicit attitude is stronger than that of explicit attitude. The study found that the explicit attitude had a better predictive power of the behavior which consciousness can control, however, as for the spontaneous or automatic behavior, the predictive power of explicit measurement greatly declined. The implicit attitude can better predict the automatic behavior. The results seem to well prove our hypothesis of double process of implicit and explicit attitude. The assumption is that the explicit attitude influences the consciousness which can control one's behavior, while the implicit attitude influences the automatic reaction. However, it should be pointed out that the study found that implicit attitude also had a good predictive power of the behavior that was controlled by consciousness. All in all, the implicit attitude seems can both influence the automatic response and affect the active or conscious behavior; however, the explicit attitude is more likely to act on the behavior that consciousness can control.

Based on the above theory, love belongs to the social topic with strong social sensitivity, and many who have experienced love can find that the person who accompanies them at last is not the one that is stipulated in their ideals. It also shows that emotion is the behavior that cannot be controlled by consciousness. What's more, in the chi-square test we have learned that the implicit attitude and explicit attitude have significant differences, and the two show weak correlation. Study shows that when the two have low correlation, the predictive power of attitude acting on behavior will reduce. For the love outlook, implicit attitude has more persuasion of predicting. So to some extent, the implicit attitude has more predictive power than the explicit attitude on love outlook.

\section{REFERENCES}

[1] ZHOU Yu-lin, XIAO Hai-yan, and WU Yi, "On Instruction of College Students on Love Concept in Social Transition Period," Journal of Shanxi Agricultural university(Social Science Edition), vol.10, Feb.2011,pp.153-156.

[2] LIU Cong-Ying and ZOU Hong,"Review of Foreign Love View, ” Social Sciences Abroad, June. 2009,pp.102-107 .

[3] LIN Yan-yan and LI Zhao-xu,"Outline of Love Theories in the Field of Psychology,” Journal of Gannan Teachers College, Jan.2006,pp. 40-44

[4] LIU Jun-sheng and Sang Biao,"The Relationship Between The Implicit Attitude and The Explicit Attitude and Behavior Prediction ," Journal of East China Normal University ( Educational Sciences), vol.28, Feb.2010,pp. 59-66.

[5] Sun $\mathrm{Ni}$, "Implicit Association Test of shyness and the study of the feature of facial cognitive task by the individuals of different shyness level,'The master's degree thesis of Shan Dong Normal University, 2011.

[6] CAO Hui, SHI Zhan-biao, and ZHANG Jian-xin,“ Revise the Love Attitude Scale in Chinese Students by IRT ,”Chinese Journal of Clinical Psychology, vol.. 15, May.2007,pp. 459-462.

[7] REN Bing-hai and HUANG Zhen-zhen,"Survey of Implicit Association Test,"Journal of the exam, vol.24, 2007,pp. 124.

[8] LIN Jia-li, "Is the Implicit Attitude an effective predicting tool that is independent from the Explicit Attitude? -A proof from the study of the Intergenerational Influence on the attitude toward brands," The master's degree thesis of East China Normal University, 2010.

[9] LI Xi-Ying, WANG Xiao-Li, ZHAO Yu-Huan, and XU QingLin,"A Review on the New Variants of Implicit Association Test: Based on the Normative Analysis,"Advances in Psychological Science, vol.19, May.2011,pp. 749-754.

[10] GUAN Qin,"Deviate and Correct The Love Attitude and The Act of Love," The Modern Education Management, March.2011,pp. 98-100. 